\title{
Methylation profiling of twenty promoter-CpG islands of genes which may contribute to hepatocellular carcinogenesis Jian $\mathrm{Yu}^{1}$, Min $\mathrm{Ni}^{1}$, Jian $\mathrm{Xu}^{1}$, Hongyu Zhang ${ }^{1}$, Baomei Gao1, Jianren $\mathrm{Gu}^{1}$, Jianguo Chen ${ }^{2}$, Lisheng Zhang ${ }^{3}$, Mengchao $\mathrm{Wu}^{4}$, Sushen Zhen ${ }^{5}$ and Jingde $\mathrm{Zhu}^{*} \mathrm{I}$
}

Address: ${ }^{1}$ The State-Key Laboratory for Oncogenes and Related Genes, Shanghai Cancer Institute, LN 2200/25, Xie-Tu Road, Shanghai 200032, China, ${ }^{2}$ Qidong Liver Cancer Institute, Qidong 226200, China, ${ }^{3}$ Guangxi Cancer Institute,, Guangxi 530021, China, ${ }^{4}$ Eastern Hepatobiliary Surgery Hospital, Shanghai 200433, China and ${ }^{5}$ The First Affiliated Hospital, College of Medicine, Zhejiang University, Zhejiang 310003 , China

Email: JianYu - gyujian@citi2.net; Min Ni - nimin516@hotmail.com; Jian Xu - xhujian626@hotmail.com; Hongyu Zhang - hyzhang@sh163.net; Baomei Gao - gaobaomei@yahoo.com; Jianren Gu - nlorg@public.sta.net.cn; Jianguo Chen - chenjg@eastdau.com; Lisheng Zhang - lishenzhang@sina.com; Mengchao Wu - mcwu@public.sta.net.cn; Sushen Zhen - zhengss@mail.hz.zj.cn; Jingde Zhu* - zhujingde@yahoo.com

* Corresponding author

Published: 15 November 2002

BMC Cancer 2002, 2:29
Received: 30 July 2002

Accepted: 15 November 2002

This article is available from: http://www.biomedcentral.com/I47I-2407/2/29

(C) 2002 Yu et al; licensee BioMed Central Ltd. This is an Open Access article: verbatim copying and redistribution of this article are permitted in all media for any purpose, provided this notice is preserved along with the article's original URL.

\begin{abstract}
Background: Hepatocellular carcinoma (HCC) presents one of the major health threats in China today. A better understanding of the molecular genetics underlying malignant transformation of hepatocytes is critical to success in the battle against this disease. The methylation state of $C 5$ of the cytosine in the $C_{p} G$ di-nucleotide that is enriched within or near the promoter region of over $50 \%$ of the polymerase II genes has a drastic effect on transcription of these genes. Changes in the methylation profile of the promoters represent an alternative to genetic lesions as causative factors for the tumor-specific aberrant expression of the genes.
\end{abstract}

Methods: We have used the methylation specific PCR method in conjunction with DNA sequencing to assess the methylation state of the promoter $C_{P G}$ islands of twenty genes. Aberrant expression of these genes have been attributed to the abnormal methylation profile of the corresponding promoter CpG islands in human tumors.

Results: While the following sixteen genes remained the unmethylated in all tumor and normal tissues: CDHI, APAFI, hMLHI, BRCAI, hTERC, VHL, RAR $\beta$, TIMP3, DAPKI, SURVIVIN, pI 4ARF, RBI, pI5INK4b, APC, RASSFIc and PTEN, varying degrees of tumor specific hypermethylation were associated with the pI6INK4a , RASSFIa, CASP8 and CDHI3 genes. For instance, the pl $6^{1 N K 4 a}$ was highly methylated in HCC $(17 / 29,58.6 \%)$ and less significantly methylated in non-cancerous tissue (4/29. 13.79\%). The RASSFla was fully methylated in all tumor tissues $(29 / 29,100 \%)$, and less frequently methylated in corresponding noncancerous tissue $(24 / 29,82.75 \%)$.

Conclusions: Furthermore, co-existence of methylated with unmethylated DNA in some cases suggested that both genetic and epigenetic (CPG methylation) mechanisms may act in concert to inactivate the pI 6INK4a and RASSFIa in HCC. Finally, we found a significant association of cirrhosis with hypermethylation of the pI6INK4a and hypomethylation of the $\mathrm{CDHI} 3$ genes. For the first time, the survey was carried out on such an extent that it would not only provide new insights into the molecular mechanisms underscoring the aberrant expression of the genes in this study in HCC, but also offer essential information required for a good methylation-based diagnosis of HCC. 


\section{Background}

Hepatocellular carcinoma (HCC) presents a major health threat in South-East Asia, especially in China. It rates third among all malignancies both in incidence and modality in China and accounts for approximately $42.5 \%$ of the total incidence worldwide $[1,2]$. Its rapidly advancing nature makes early detection a crucial prognostic factor. Despite many years of sustained efforts, the long-term outcome employing current therapies remains dismal as both recurrences of the lesions within the liver and distant metastases are not rare occurrences. Both chronic hepatitis $\mathrm{B}$ viral infection and exposure to $\alpha$-flatoxin $\mathrm{B} 1$ are the two most important risk factors associated with this disease [3].

Cancer is a disease in which cells suffer from multiple genetic changes resulting in the aberrant expression of many genes which in turn form tumor specific phenotypes [47]. Mechanistically, the methylation mediated gene silencing mechanism can contribute to the tumor specific profile of gene expression, as a common alternative to genetic changes. In higher vertebrates, the major, if not the only, covalent modification of DNA is the C5 methyl cytosine within the $\mathrm{CpG}$ di-nucleotides which are significantly under-represented in genomes but frequently concentrated within short pieces of DNA segments, designated as "CpG islands" [6,8]. The enzymes responsible for this chemical reaction are the DNA methyl transferase I and IIIA as well as IIIB [6,8]. The DNA methyl transferase I is mainly involved in maintenance of the methylation status of genomes through DNA replication, whereas DNA methyl transferase IIIA and IIIB act principally for the de novo DNA methylation in the early stages of development $[6,7]$. Over $50 \%$ of the protein coding genes have at least one CpG island within or near their promoters, expressions of which are sensitive to the methylation status of such CpG islands [7]. The methylation profiles of the promoter CpG islands have been useful indicators for the transcriptional state of the genes in a large number of, if not all, cases. The hypermethylated promoters lack the transcriptional activity that may account for gene inactivation both in normal physiological and disease states, noticeably the inactivation of the tumor suppressor genes in cancers [7,9-11]. Elevated levels of expression of the DNA methyl transferase I have been frequently observed in cancers and may have a causal role in hypermethylation-mediated gene silencing of the tumor suppressor genes. On the other hand, the genes that lack expression and have hypermethylated promoter CpG islands in normal cells may be reactivated by promoter demethylation in tumor cells [7]. However, there was evidence for the global level of hypomethylation in tumors, the consequence of which is genome instability in tumor cells $[12,13]$. Therefore, there must be a gene-specific mechanism for determining the methylation profile of the promoter CpG islands both in normal and tumor cells, which correlates well with the expression profile of the genes.

Many recent studies demonstrated that the DNA methylation based mechanism can contribute to inactivation of tumor suppressor genes, key event in tumorgenesis of a wide spectrum of human tumors [7,9-11], including HCC $[14,15]$. However, the overwhelming majority of, if not all, such studies have dealt with only one or just a few genes. This was particularly true in regard to human HCC for which only p16 $16^{\mathrm{INK}} 4 \mathrm{a}, \mathrm{p} 15^{\mathrm{INK}} 4 \mathrm{~b}$ and $\mathrm{p} 14^{\mathrm{ARF}}$ genes have been investigated $[15,16]$. Previously, whether there were any associations in the methylation profiles of different genes may have been an impossible issue to address. In this report, we surveyed the methylation profiles for as many as twenty genes in both HCC tissues and adjacent non-cancerous tissues of twenty-nine patients (Table 1). Furthermore, we included the DNA from four healthy donors as the most stringent control for the pattern of promoter $\mathrm{CpG}$ island methylation in normal liver tissues. Sixteen genes including CDH1, APAF1, hMLH1, BRCA1, hTERC, VHL, RAB $\beta$, TIMP3, DAPK1, SURVIVIN, p14ARF, RB1, p15 INK4b, APC and PTEN had the same DNA methylation pattern in all samples, including the cancerous and corresponding non-cancerous tissue from patients as well as the normal liver tissue from healthy donors. The methylation mediated mechanisms, therefore, may have no significant roles to play in expression of these sixteen genes in HCC. On the contrary, the methylation profiles of the p16INK4a, RASSF1a, CDH13 and CASP8 genes varied with the patient samples to varying degrees. Furthermore, among all possible associations with the clinicalpathological parameters being considered, we found a tight link between hypermethylated p16 INK4a and hypomethylated CDH13 on one hand and cirrhosis on the other. Our results should not only enhance our understanding of the molecular epigenetic mechanisms underscoring hepatocarcinogenesis, but also facilitate the development of robust early diagnostic tools based on the DNA methylation profile for human HCC in China.

\section{Methods \\ Cell lines and tissue samples}

With the informed consent of all patients and donors and approval of the ethics committee, the samples of tumor and adjacent non-cancerous tissues were collected from HCC patients $(n=29)$ (Table 1$)$ during surgery at The Qidong County Hospital, The Oriental Institute for Liver Diseases and Guangxi Provincial Hospital, respectively. In addition, normal liver tissues $(n=4)$ were obtained from liver donors at the Liver Transplantation Unit in The First Affiliated Hospital, College of Medicine, Zhejiang University The pathological classification of HCC tissues was carried out and the stage of each HCC was determined 
Table I: Clinical pathological parameters of HCC patients

\begin{tabular}{|c|c|c|c|c|c|c|c|}
\hline No. & Patient & Age & Sex & Cirrhosis & HBV infection & $\begin{array}{c}\text { AFP } \\
\text { (serum level) }\end{array}$ & Grading \\
\hline I & DI & 56 & $M$ & - & + & $10.9 \mu \mathrm{g} / \mathrm{l}$ & 1 \\
\hline 2 & DI4 & 33 & $\mathrm{~F}$ & - & + & $1000 \mu \mathrm{g} / \mathrm{I}$ & II \\
\hline 3 & DI5 & 65 & $\mathrm{~F}$ & + & + & 183. $\mu g / /$ & $\|$ \\
\hline 4 & DI6 & 51 & $M$ & + & + & $2590 \mu \mathrm{g} / \mathrm{l}$ & I \\
\hline 5 & DI7 & 37 & $M$ & + & + & $1000 \mu g / 1$ & III \\
\hline 6 & DI8 & 61 & $M$ & - & + & $2.5 \mu \mathrm{g} / \mathrm{l}$ & 1 \\
\hline 7 & D24 & 36 & $M$ & + & + & $10.6 \mu g / 1$ & III \\
\hline 8 & D59 & 70 & $M$ & + & + & $27.6 / \mu g / l$ & I \\
\hline 9 & Z82 & 55 & $\mathrm{~F}$ & + & + & $385 \mu g / l$ & I \\
\hline 10 & Z85 & 57 & $M$ & + & + & $415 \mu g / l$ & \\
\hline II & Z89 & 42 & $M$ & + & + & $10 \mu \mathrm{g} / \mathrm{l}$ & III \\
\hline 12 & Z90 & 67 & $M$ & + & + & $14|\mu g /|$ & II \\
\hline 13 & Z92 & 44 & $M$ & + & + & $1208 \mu g / \mid$ & II \\
\hline 14 & G33 & 36 & $\mathrm{~F}$ & + & + & $400 \mu g / l$ & II \\
\hline 15 & G35 & 38 & $M$ & + & + & $12 \mu \mathrm{g} / \mathrm{|}$ & II \\
\hline 16 & G36 & 72 & $M$ & + & + & $1416 \mu \mathrm{g} / \mathrm{l}$ & I \\
\hline 17 & G4I & 56 & $M$ & + & + & $10 \mu g / l$ & 1 \\
\hline 18 & G44 & 62 & $M$ & + & + & $10 \mu \mathrm{g} / \mathrm{l}$ & II \\
\hline 19 & G47 & 44 & $M$ & - & + & $346 \mu g / l$ & 1 \\
\hline 20 & G62 & 46 & $M$ & - & + & $16 \mu \mathrm{g} / \mathrm{l}$ & II \\
\hline 21 & G63 & 42 & $M$ & - & + & $3.7 \mu \mathrm{g} / \mathrm{l}$ & III \\
\hline 22 & G64 & 42 & $M$ & - & + & $4000 \mu \mathrm{g} / \mathrm{l}$ & II \\
\hline 23 & G65 & 35 & $\mathrm{~F}$ & - & + & $400 \mu g / l$ & III \\
\hline 24 & Q45 & 61 & $M$ & - & + & $400 \mu \mathrm{g} / \mathrm{l}$ & II \\
\hline 25 & Q46 & 50 & $\mathrm{~F}$ & - & + & $400 \mu \mathrm{g} / \mathrm{l}$ & II \\
\hline 26 & Q47 & 52 & $M$ & - & + & $30 \mu \mathrm{g} / \mathrm{l}$ & ॥ \\
\hline 27 & Q48 & 48 & $M$ & - & + & $38 \mu \mathrm{g} / \mathrm{l}$ & I \\
\hline 28 & Q49 & 42 & $M$ & - & + & $400 \mu \mathrm{g} / \mathrm{l}$ & II \\
\hline 29 & $\times 63$ & 37 & $M$ & + & + & & II \\
\hline
\end{tabular}

according to criteria outlined by the Liver Cancer Study Group of Japan[40].

Total genomic DNA was extracted from frozen tissue specimens (50 - $100 \mathrm{mg}$ ) according to standard protocol [18] with some modifications, which are briefly described below. Frozen pulverized powders of the specimens were resuspended with $2 \mathrm{ml}$ warmed lysis buffer: $50 \mathrm{mM}$ Tris$\mathrm{HCl} \mathrm{pH}$ 8.0, $50 \mathrm{mM}$ EDTA, 1\% SDS, $10 \mathrm{mM} \mathrm{NaCl}$ plus $100 \mu \mathrm{g} / \mathrm{ml}$ boiling-treated RNase A (Sigma). Following one hour of incubation at $37^{\circ} \mathrm{C}$, Proteinase $\mathrm{K}$ (Roche, USA) was added to the cellular lysates for a final concentration of $100 \mu \mathrm{g} / \mathrm{ml}$ and the digestion was carried out at $55^{\circ} \mathrm{C}$ for 2 hours. Organic extractions with a half volume of Phenol/Chloroform/Isoamyl alcohol (1:1:0.04) were repeatedly carried out until no visible interphase remained after centrifugation. DNA was precipitated from the aqueous phase in the presence of $0.3 \mathrm{M} \mathrm{NaOAc} \mathrm{pH} 7.0$ and two and a half volumes of ethanol. The DNA pellet was washed once with $70 \%$ ethanol and dissolved at $65^{\circ} \mathrm{C}$ for 30 minutes with $0.2-0.4 \mathrm{ml}$ TE $(10 \mathrm{mM}$ Tris $\mathrm{HCl} \mathrm{pH} 7.4$ and $1 \mathrm{mM}$ EDTA), followed by storage at $4^{\circ} \mathrm{C}$ until further use. The DNA concentrations were calculated according to their OD260nm readings.

The genomic DNA was also prepared from tumor cell lines: SMMC 7721 (an established human cell line from a human hepatocellular carcinoma, Catalogue No, TCHu13 in Cell Bank in China), HuH-7 (a human liver cancer cell line, JCRC No. JCRB0403), Hep 3B (a human hepatoma cell line, ATCC No., HB-8064), Hep G2 (a human hepatoma cell line, ATCC No., HB-8065) and U20s (an osteosarcoma cell line, ATCC No.HTP96,) and stored in TE buffer at $4^{\circ} \mathrm{C}$

\section{Bisulphate treatment of DNA and MSP}

The methylation status of the promoter CpG islands of twenty genes (Additional file 1) in all sample DNA were analyzed by MSP on the sodium-bisulfite converted DNA [18]. All chemicals at analytic grade were obtained from Shanghai Chemical Cooperation, China and the experimental procedure was customized by using genomic DNA of SMMC7721 and U20S cells. In detail, $10 \mu \mathrm{g}$ DNA in 50 $\mu \mathrm{l}$ TE was incubated with $5.5 \mu \mathrm{l}$ of $3 \mathrm{M} \mathrm{NaOH}$. at $37^{\circ} \mathrm{C}$ for 
Table 2: Clinical pathological considerations of HCC sub-groupings according to geographic origin

\begin{tabular}{|c|c|c|c|c|c|c|c|}
\hline & \multicolumn{2}{|c|}{ Sex } & \multicolumn{3}{|c|}{ Grading } & \multicolumn{2}{|c|}{ Cirrhosis } \\
\hline & $\mathrm{F}$ & $M$ & 1 & II & III & + & - \\
\hline $\begin{array}{l}\text { SHANGHAI } \\
(n=19)\end{array}$ & 4 & 15 & 5 (28\%) & $8(44 \%)$ & $5(28 \%)$ & II (58\%) & $8(42 \%)$ \\
\hline $\begin{array}{c}\text { GUANGXI } \\
(n=10)\end{array}$ & 2 & 8 & $3(30 \%)$ & $4(40 \%)$ & $3(30 \%)$ & $5(50 \%)$ & $5(50 \%)$ \\
\hline
\end{tabular}

*The total cirrhosis positive rate is $16 / 29$ (55\%)

10 minutes, followed by a 16 hour treatment at $50^{\circ} \mathrm{C}$ after adding $30 \mu \mathrm{l}$ of freshly prepared $10 \mathrm{mM}$ hydroquinone and $520 \mu \mathrm{l}$ of freshly prepared $3.6 \mathrm{M}$ sodium-bisulfite at pH 5.0. The DNA was desalted using a home dialysis system with $1 \%$ agarose (detailed protocol will be provided upon request). The DNA in the desalted sample (approximately $100 \mu \mathrm{l}$ in volume) was denatured at $37^{\circ} \mathrm{C}$ for 15 minutes with $5.5 \mu \mathrm{l}$ of $3 \mathrm{M} \mathrm{NaOH}$ followed by ethanol precipitation with $33 \mu \mathrm{l} 10 \mathrm{M} \mathrm{NHaOAC}$ and $300 \mu \mathrm{l}$ ethanol. After washing with $70 \%$ ethanol, the gently dried DNA pellet was dissolved with $30 \mu \mathrm{l} \mathrm{TE}$ at $65^{\circ} \mathrm{C}$ for 10 min. The DNA sample was finally stored at $-20^{\circ} \mathrm{C}$ until further use. The sample of $50 \mathrm{ng}$ of DNA was reserved for PCR reaction.

PCR reaction was carried out in a volume of $15 \mu \mathrm{l}$ with 50 ng or less template DNA with FastStart Taq polymerase (Roche, Germany) as follows. After an initial heat denaturing step 4 minutes treatment at $94^{\circ} \mathrm{C}$ ), 30 cycles of $92^{\circ} \mathrm{C}$ for $15 \mathrm{sec}$, varying temperatures with primer pairs (Additional file 1) for $15 \mathrm{sec}$ and $72^{\circ} \mathrm{C}$ for $20 \mathrm{sec}$, was carried out. The PCR products were separated by $1.2 \%$ ethidium bromide containing agarose gel electrophoresis with $1 \mathrm{X}$ TAE and visualized under UV illumination. To verify the PCR results, representative bands from each target were gel-purified and cloned into T-vector (Promega, USA) followed by automatic DNA sequencing provided by Genecore (Shanghai, China). Only verified results are presented in this report.

Southern analyses with the methylation sensitive enzyme of the promoter CPG islands of the pI4ARF and p/5 INK4b genes in hepatoma cell lines

30 microgram of the genomic DNA from the HepG2, Hep $3 \mathrm{~B}$, and $\mathrm{HuH}-7$ cell lines were digested to completion with BstX I (for p14 ${ }^{\mathrm{ARF}}$ ) and Hind III (for p15 ${ }^{\mathrm{INK} 4 \mathrm{~b}}$ ), respectively. Following ethanol precipitation, 10 microgram of the digests was restricted to completion with Hap II and Msp I enzymes, respectively. The digested DNA was ethanol precipitated and subjected to Southern analysis according the previously published protocol [43].
The DNA fragments for the hybridization probes were made by PCR reaction on the HepG2 DNA. The primers are ordered according to the genomic sequence of the relevant gene locus (Accession No. AL449423 in GenBanK), namely, 1, for the p14ARF gene: the sense: 5' GAG TTT GAG CAT GTG CAA TGT TAG G 3'; the anti-sense: 5' GGG ATT ATT ACT CCT GTT TTA CAG GTG 3'; 475bp in size (89561-90035) and 2, the p15 INK4b: the sense : $5^{\prime}$ CCT GTT TTA CGC GTG GAA T 3' and the anti-sense: 5' TAA TGA AGC TGA GCC CAG GT 3'; 437bp in size (9939199827). The resulted PCR fragments were labeled with the random labeling kit (Roch, Germany) in presence of ${ }^{32} \mathrm{p}$ dCTP (Amersham, UK). The labeled probes were chromatographically purified from free nucleotides, heat-denatured, hybridized to the blots. The post-hybridization washing of the membranes was carried out with $1 \mathrm{X} \mathrm{SSC}$, $0.1 \%$ SDS at $42{ }^{\circ} \mathrm{C}$ for 30 minutes for three times. The hybridized bands were revealed in the phosphoimager Typhoon 9410(Molecular dynamics, USA).

\section{Results and Discussion Clinical-pathological considerations}

The geographical occurrence of HCC varies dramatically within China. In areas such as Qidong county near Shanghai and Guangxi province, well known high incidence areas, the annual incidence of HCC is as high as $70-96 /$ 10,0000 and approximately eight to nine fold higher than that of low incidence areas within China $[1,3]$. Two common risk factors identified in these regions are persistent hepatitis B viral infections and $\alpha$-flatoxin B contamination of food stocks[3]. To address the geographic aspect of this disease, we deliberately recruited nineteen patients in Shanghai area (including eight patients from Qidong county) and ten patients from GuangXi province in the southern part of China. As shown in Table 1, all patients were $\mathrm{HBV}$ infected verified by both serological analysis and the PCR test for existence of the HBV X gene in tumor tissue (not shown). As indicated in Table 2, no significant differences for any of the clinical pathological indicators between these two geographically classified patient groups were detected. For instance, male patients accounted for $78.9 \%$ and $80 \%$, cirrhosis occurred in $58 \%$ and 50 
Table 3: Cirrhosis and methylation profiles of the genes in HCC tissues

\begin{tabular}{|c|c|c|c|c|c|c|}
\hline Patient & Cirrhosis & Grading & CDHI3 & pl6INK4a & RASSFIA & CASP8 \\
\hline D24 & + & III & $U$ & $M$ & $M$ & $M$ \\
\hline DI7 & + & III & $U$ & $M$ & $M$ & $M$ \\
\hline$\times 63$ & + & II & $U$ & $U$ & $M$ & \\
\hline Z89 & + & III & $U$ & $M$ & $M$ & $M$ \\
\hline Z92 & + & II & $M$ & $M$ & $M$ & $M$ \\
\hline DI6 & + & 1 & $U$ & $U$ & $M$ & $M$ \\
\hline Z82 & + & I & $U$ & $M$ & $M$ & \\
\hline Z85 & + & & $U$ & $M$ & $M$ & \\
\hline DI5 & + & II & $U$ & $M$ & $M$ & $M$ \\
\hline Z90 & + & II & $U$ & $M$ & $M$ & $M$ \\
\hline D59 & + & I & $U$ & $M$ & $M$ & $M$ \\
\hline G33 & + & II & $U$ & $U$ & $M$ & $M$ \\
\hline G35 & + & II & $U$ & $M$ & $M$ & $M$ \\
\hline G4I & + & I & $U$ & $M$ & $M$ & $M$ \\
\hline G44 & + & II & $U$ & $U$ & $M$ & \\
\hline G36 & + & I & $U$ & $M$ & $M$ & $M$ \\
\hline Total (\%) & $\mathrm{C} / \mathrm{T}(\mathrm{I} 6) 100 \%$ & & $\mathrm{M} / \mathrm{T}(16) 6.25 \%$ & $M / T(16) 75 \%$ & $\mathrm{M} / \mathrm{T}(\mathrm{I} 6) 100 \%$ & $M / T(I 2) 100 \%$ \\
\hline DI8 & - & I & $M$ & $U$ & $M$ & $M$ \\
\hline Q45 & - & II & $U$ & $\cup$ & $M$ & \\
\hline G65 & - & III & $U$ & $U$ & $M$ & \\
\hline DI & - & 1 & $U$ & $M$ & $M$ & $M$ \\
\hline Q47 & - & II & $M$ & $M$ & $M$ & $M$ \\
\hline G63 & - & III & $U$ & $M$ & $M$ & $M$ \\
\hline G64 & - & II & $U$ & $U$ & $M$ & \\
\hline G47 & - & 1 & $U$ & $U$ & $M$ & $M$ \\
\hline G62 & - & III & $M$ & $M$ & $M$ & $M$ \\
\hline DI4 & - & II & U & 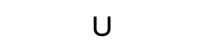 & $M$ & $M$ \\
\hline Q49 & - & II & $U$ & $\cup$ & $M$ & \\
\hline Q48 & - & I & $M$ & $U$ & $M$ & $M$ \\
\hline Q46 & - & II & $M$ & $\cup$ & $M$ & \\
\hline Total (\%) & $\mathrm{C} / \mathrm{T}(\mathrm{I}) 0 \%$ & & $\mathrm{M} / \mathrm{T}(\mathrm{I} 3) 38.46 \%$ & $M / T(13) 30.76 \%$ & $\mathrm{M} / \mathrm{T}(\mathrm{I} 3) 100 \%$ & $\mathrm{M} / \mathrm{T}(8) 100 \%$ \\
\hline
\end{tabular}

$\%$ of patients and diagnoses of grade I were $28 \%$ and $30 \%$, grade II were $44 \%$ and $40 \%$ and grade III were $28 \%$ and $30 \%$ of the Shanghai and Guang Xi patient groups, respectively. Therefore, the remaining analyses were carried out without any consideration of geographic impact.

Special efforts were made to include the corresponding non-cancerous tissues, samples of which were overlooked in all previous studies of HCC $[14,15]$. Furthermore, pathological examination of the tissues had been carried out to eliminate samples in which contamination of undesirable tissues exceeded 20\%. To emphasize the HCC specificity of this study, four samples of normal liver tissue were collected from the Liver Transplantation Unit of the Zhejiang First Hospital as the normal liver control.
The genes with no HCC associated alteration in the methylation profiling

Among several dozens of targets in the category of the CpG island containing genes http://www.missouri.edu/ whypermet/list_of_promoters.htm, we assessed the promoter CpG islands of twenty genes well recognized for their roles in carcinogenesis and expressions of which are affected by the methylation status of each promoter CpG island. There are TSP genes in the RB/p16 pathway: RB1, p16 INK4a and p15 INK4b; in the p53 pathway: p14 ${ }^{\mathrm{ARF}}$; genes involved in intercellular interaction: $\mathrm{CDH} 1$, CDH13, TIMP3 and RAR- $\beta$; genes involved in DNA repair: hMLH1, and BRCA1; genes involved in apoptosis, APAF1, DAPK1, CASP8 and SURVIVIN and several other TSP genes: RASSF1a and RASSF1c, VHL, APC and PTEN. Finally, the hTERC gene was included in this study, the encoded RNA of which is the key component of the telomerases acting against replication dependent shortening of telom- 
eres and the over-expression of which correlates with demethylation of the promoter CpG islands in human breast carcinoma [17].

Differing from the methylation-sensitive restriction enzymes that are limited to a subset of CpG-cytosine, methylation specific PCR (MSP) in conjunction with sequencing allows the analysis of the methylation status of all the CpGs within the targeted CpG islands. MSP distinguishes unmethylated from methylated alleles based on the sequence changes created by bisulfite treatment of DNA, which are recognized by PCR with one of two pairs of primers designated for either methylated or unmethylated DNA. [18] To ensure the relativity of our study with others $[9,10,18-26]$, we chose the same CpG regions selected by other researchers as study targets (see Additional file 1). For genes not previously investigated, the primers were designed with special care in regard to both location and size of CpG islands. As shown in Additional file 1, the genes in this category are APAF1, CDH13, PTEN, RASSF1c and SURVIVIN. Finally, the representative methylated and unmethylated PCR products were cloned into T-vectors and sequenced for data verification. Since all DNA samples were batch-treated chemically and analyzed with each of 40 pairs of primers using the MSP approach respectively, observations from each PCR reaction were mutually controlled by each of the remaining 39 PCR reactions with different pairs of primers. Therefore, the influences over experimental data have been well eliminated by factors including the under- or over-treatment of DNA by sodium-bisulfite; contamination of the undesired types of tissues to the samples should have been minimized.

As indicated in both Fig. 1, Fig. 2 and Additional file 2, sixteen targets including p14 $\mathrm{ARF}$ (Fig. 1, panel 1), p15 INK4b (Fig. 1, panel 2), SURVIVIN (Fig. 1, panel 7), TIMP3 (Fig. 1, panel 8), VHL (Fig. 1, panel 9), APC (Fig. 2, panel 1), RASSF1c (Fig. 1, panel 10)APAF1 (Fig. 2, panel 2), BRCA1 (Fig. 2, panel 3), DAPK1 (Fig. 2, panel 4), CDH1 (Fig. 2, panel 5), hMLH1 (Fig. 2, panel 6), hTERC (Fig. 2, panel 7), PTEN (Fig. 2, panel 8), RAR- $\beta$ (Fig. 2, panel 9), and RB1 (Fig. 2, panel 10), had a consistent pattern among all tissues tested, including cancerous and counterpart noncancerous tissues from twenty-nine patients with hepatocarcinoma along with donated normal liver tissue from four healthy controls. All the targets in this category were unmethylated, which came as a surprise in view of many recent published data showing that a significant proportion of tumor cases, from a large spectrum of tissue origins, had one or several genes in the list inactivated via the methylation mediated genes silencing mechanism. One may consider all the following plausible explanations. 1. These genes may not have had any significant role to play in carcinogenesis of the human HCC and did not suffer any functional loss in cancerous tissues due to any genetic or epigenetic mechanisms. 2. The defects of the pathways where these genes preside had been caused by genetic or epigenetic aberrations targeted to the genes acting either upstream or downstream of the genes listed. 3. The functional loss of these genes may indeed happen in HCC, but the mechanism involved is not related to DNA methylation. 4. Again, the functional loss of these genes which happens in HCC may be attributed to methylation-mediated gene silencing mechanisms. However, the changes in methylation profile may have occurred at the CpG island rather than the one being analyzed in this report. Obviously, which of the aforementioned mechanisms contributed to the observed methylation profile for each of these sixteen genes (Fig. 1 and 2 and Additional file 2) remains to be determined. Tumor specific inactivation of these sixteen genes caused by hypermethylation of the promoter CpG island has been widely claimed in a variety of solid tumors. For instance, the TIMP3 gene encodes an inhibitor of metalloproteinase 3 and is thought to suppress primary tumor growth $[23,29]$. Its promoter $\mathrm{CpG}$ island was methylated in $19-26 \%$ of the non-small cell lung cancers[23]. The lack of hypermethylation of all these promoter CpG islands in our study of human HCC may have differential diagnostic value between human HCC and other human tumors when a serum DNA-methylation profiling-type diagnostic assay has been developed.

Wong et al. have reported that the promoter CpG islands of the $\mathrm{p} 14^{\mathrm{ARF}}$ and $\mathrm{p} 15^{\mathrm{INK}} 4 \mathrm{~b}$ were methylated in a significant percentage of HCC cases in Hong Kong [14,15], while neither were methylated in this study (Fig. 1 and 2 and Additional file 2). As the target $\mathrm{CpG}$ islands in these two studies are identical and our MSP results were verified by DNA sequencing, the discrepancy between our work and that of Wong may reflect the difference in the geographical related risk factors between Hong Kong and Shanghai/Guangxi. However, to eliminate a remote possibility that failure to detect the methylated CpG islands of these two genes in our hand might result from the inadequacy of the MSP approaches used in this report, we repeated this analysis with an alternative approach in which no PCR process is involved, i.e., the digested DNA with methylation sensitive enzyme (Hpa II) or insensitive enzyme (Msp I) was analyzed by Southern hybridization with the probes from the promoter $\mathrm{CpG}$ islands of the p14 ${ }^{\mathrm{ARF}}$ and p15 ${ }^{\mathrm{INK}} 4 \mathrm{~b}$, respectively (Fig. 3). We deliberately used the same enzymes and probing fragments that had been used previously $[41,42]$. Limited by the shortage of the patient's DNA samples, the genomic DNA from three established hepatoma cell lines, i.e., HepG2, Hep 3B and HuH-7 were used instead in these two experiments, the CpG islands of which were unmethyated by MSP analysis (Fig. 3, panel 2). The DNA was batched digested with Hind III (for p15 INK4b) [41] and BstX I (for p14 ${ }^{\mathrm{ARF}}$ ) [42], 


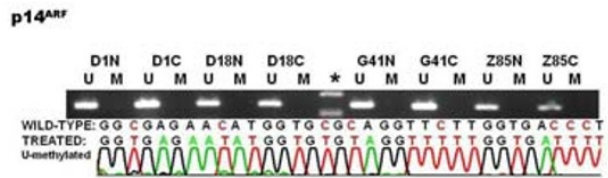

Panel 3

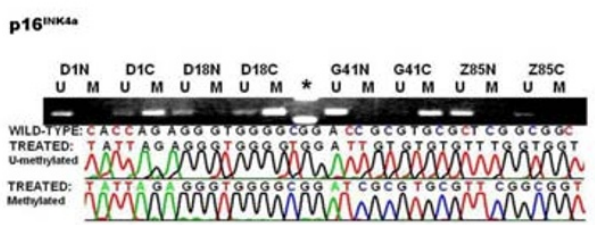

Panel 5

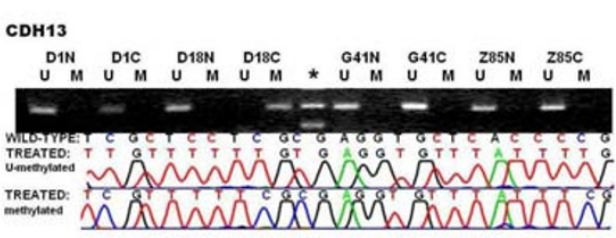

Panel 7

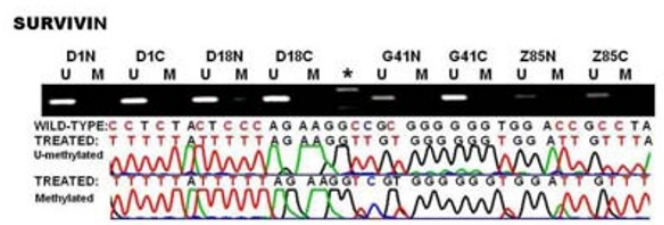

Panel 9



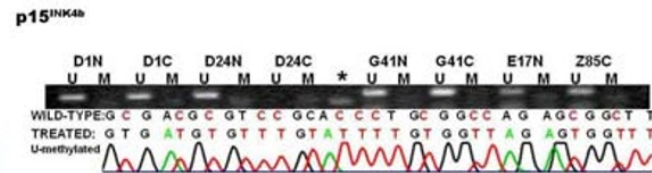

Panel 4

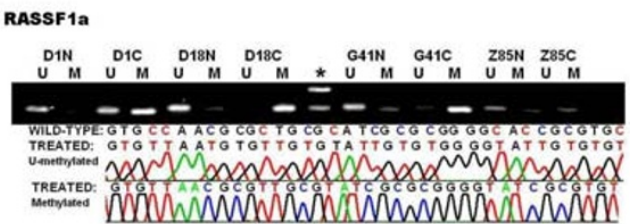

Panel 6

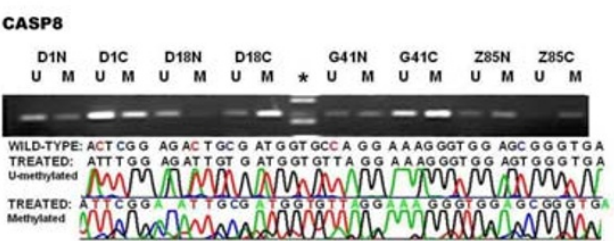

Panel 8

TIMP3

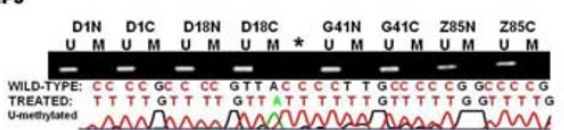

- TTTGTT TT GTATT'T'TTGTTTTTGGTTTG

Panel 10

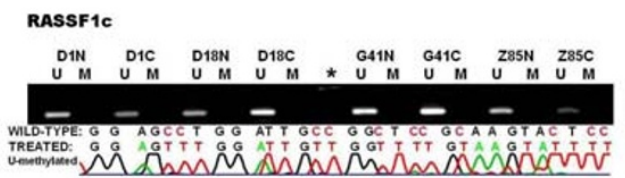

Figure I

The methylation profiles of ten genes in human HCC patients (part I). Both electrophoretic patterns of the representative PCR products of ten targets (indicated respectively at the top of figures) and the corresponding sequencing result of the one representative PCR product were presented. To indicate the methylation status, the sequenced data are aligned with the wild-type sequence. Representative samples are presented. * size marker. $U$, the unmethylated; and $M$, the methylated. 
Panel 1

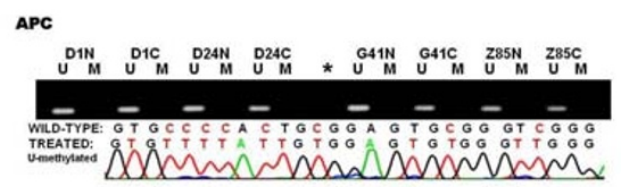

Panel 3

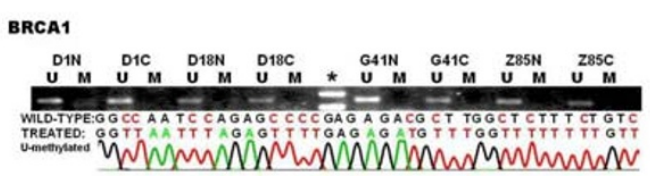

Panel 2

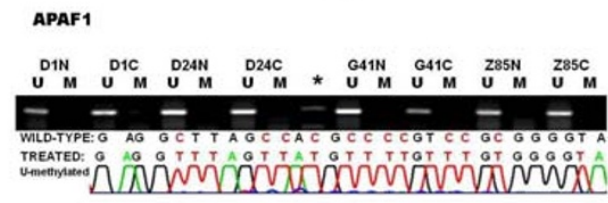

Panel 4

DAPK1

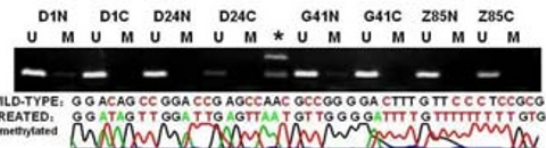

Panel 5

CDH1

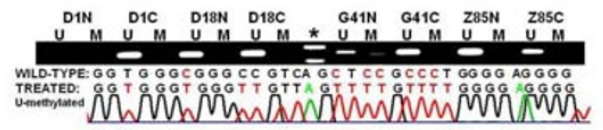

Panel 7

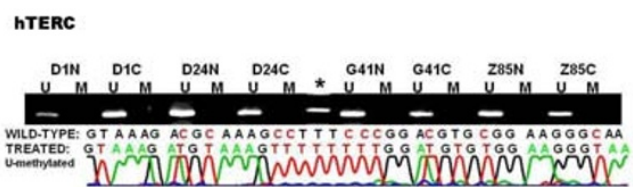

Panel 9

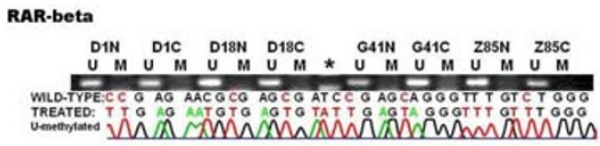

Panel 6

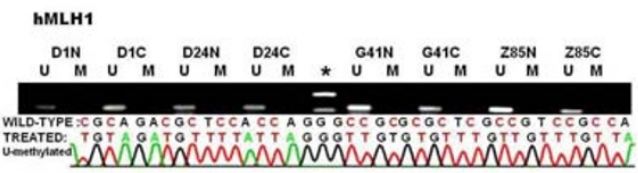

Panel 8

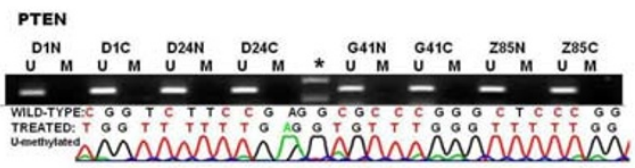

Panel 10

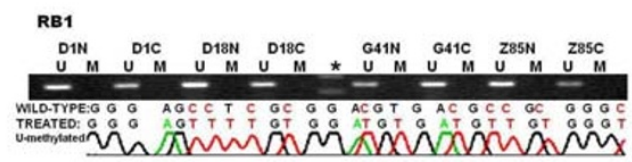

\section{Figure 2}

The methylation profiles of ten genes in human HCC patients (part 2). Both electrophoretic patterns of the representative PCR products of ten targets (indicated respectively at the top of figures) and the corresponding sequencing result of the one representative PCR product were presented. To indicate the methylation status, the sequenced data are aligned with the wild-type sequence. Representative samples are presented. * size marker. $U$, the unmethylated; and $M$, the methylated. 

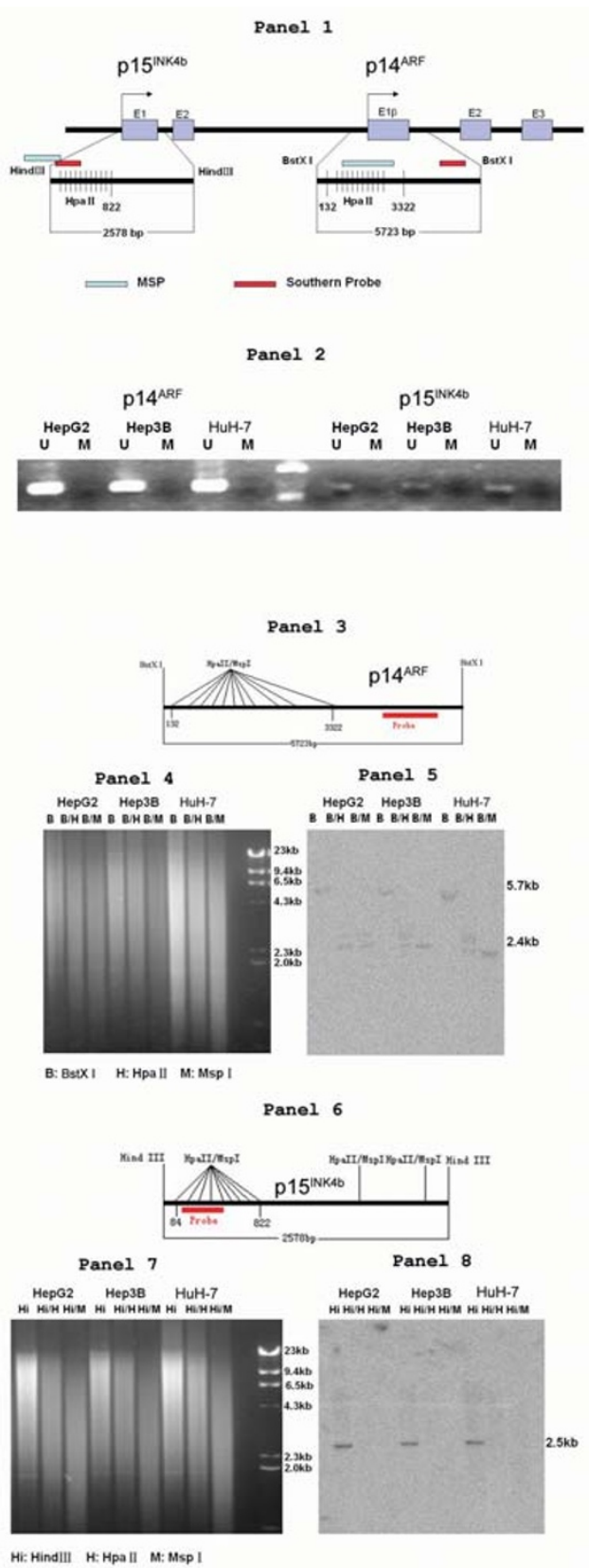

Figure 3

The methylation profiles of the p I4ARF and p I5INK4b genes in the hepatoma cell lines analyzed by both MSP and Southern analyses. Panel I, The schematic illustration of the gene structure and the $C_{p} G$ islands of interests along with restriction digestion sites and the probes. The scale is arbitrary. Panel 2, The methylation profiling of the pI4ARF and pI5INK4b promoter CpG island by MSP. Panel 3, The schematic illustration of the CPG islands of pI 4ARF with restriction digestion sites and the probes. Panel 4, The electrophoretic pattern of the digests before blotting of the genomic DNA. The cell origins of the genomic DNA are indicated at the top. The size markers are provided by Hind III digests of the lambda phage DNA and indicated in kb at the left side of the autorad. Abbreviations: B, BstX I; H: Hpa II, M: Msp I. Panel 5, The autorad of the Southern analysis hybridized by the probe indicated in panel 3. The size of the hybridized band is indicated at the left side of the antorad. Panel 6, The schematic illustration of the CPG islands of pl4ARF with restriction digestion sites and the probes. Panel 7, The electrophoretic pattern of the digests before blotting of the genomic DNA. The cell origins of the genomic DNA are indicated at the top. The size markers are provided by Hind III digests of the lambda phage DNA and indicated in kb at the left side of the autorad. Abbreviations: Hi: Hind III; H: Hpa II, M: Msp I. Panel 8, The autorad of the Southern analysis hybridized by the probe indicated in panel 6 . 
and the one third of the former digests were restricted by Hpa II (methylation sensitive) and Msp I (methylation insensitive), respectively. As shown by panels 4 and 7, Fig. 3 , the DNA for the Southern analyses were likely digested to completion and the DNA loading were fully compatible among different lanes. Both Hind III and BstX I digestion produced the fragments of the expected sizes: $5.7 \mathrm{~kb}$ in Fig. 3, panel 5 for p14 ${ }^{\mathrm{ARF}}$ and $2.5 \mathrm{~kb}$ in Fig. 3, panel 8 for $\mathrm{p} 15^{\mathrm{INK} 4 \mathrm{~b}}$. The additional digestion with Hap II or Msp I led to the disappearance of the original bands of the former single digests, suggesting the CpG islands being studied were unmethylated. Since the downstream probe of the CpG island of p14ARF (Fig. 3, panel 3) was used, the smaller fragments of approximately $2.4 \mathrm{~kb}$ in size were produced. It was noticed that the Hap II digestion produced a band bigger than that by Msp I digestion in both Hep3B and HuH-7 cells (Fig. 3, panel 5). This might result from the incomplete digestion of Hpa II. In the compatible study of the p $15^{\mathrm{INK} 4 \mathrm{~b}}$ gene, the probe was used within the CpG island (Fig. 3, panel 6), the efficient digestion by Hpa II or Msp I had resulted in loss of the parental band of the Hind III digests (Fig. 3, panel 8), again suggesting that the promoter CpG island of the $\mathrm{p} 15^{\mathrm{INK} 4 \mathrm{~b}}$ gene is unmethylated. Therefore, our conclusion based on the MSP analysis on the HCC patient samples in this report is sound.

\section{The genes with the HCC specifically altered methylation profiles}

Contrary to the sixteen genes listed above, p16INK4a, RASSF1a, CDH13 and CASP8 (panels 3-6, respectively, in Fig. 1) possessed the tumor specific altered pattern of methylation of the promoter $\mathrm{CpG}$ islands, suggesting that the DNA methylation mediated mechanisms may have a causal role in inactivation (if there is any) of the those genes in HCC in these two regions in China.

\section{The hypermethylation of the promoter CPG island of the pI GINK4a may occur at a very late stage within the multiple stage processes of hepatocellular carcinogenesis}

The p $16^{\mathrm{INK}} 4 \mathrm{a}$ is one of the most commonly inactivated tumor suppressor gene in human cancers[30] and encodes a cyclin-dependent kinase inhibitor. This tumor suppressor protein negatively regulates cell progression from the G1 to the $S$ phase by binding and inhibiting the cyclin-dependent kinases 4 and 6 , which in turn repress RB function via phosphorylation of the RB tumor suppressor protein.[28]. Hypophosphorylated RB proteins bind to the DNA bound form of the E2F/Dp-1 complexes, repressing expression of the genes, functions of which are required for cell entry from G1 to $S$ phase. Hyperphosphorylation of RB protein by cyclin-dependent kinases would dissociate RB protein from the E2F/DP1 complexes to allow the otherwise silenced transcription to occur. The paramount importance of this RB/p16 INK4a mediated control to maintain the normality of cell is vividly demonstrated by the prevalent loss of this control in human tumors $[10,23]$. Both genetic and epigenetic mechanisms resulting in inactivation of the RB1 or p16 $16^{\text {INK4a }}$ genes have been highlighted in many human tumors $[10,11,15,16,19,23,31]$. Another cyclin-dependent kinase inhibitor within the proximity of and sharing $91 \%$ sequence identity with the p $16^{\text {INK4a }}$ gene is $\mathrm{p} 15^{\mathrm{INK} 4 \mathrm{~b}}$ [32]. This $\mathrm{p} 15^{\mathrm{INK}} 4 \mathrm{~b}$ gene may have a similar tumor suppressor function as the p16 INK4a by modulating pRB phospohrylation[33], since its promoter $\mathrm{CpG}$ island was aberrantly methylated in several human tumors $[14,18,19,34]$, including the human HCC [14]. In this report, we assessed the methylation profile of the promoter $\mathrm{CpG}$ island of the RB1 (encoding TSP and RB), p16 INK4a and p15INK4b genes in the HCC samples along with the normal liver controls. As indicated in Fig. 1 and 2 and Additional file 2, the promoter $\mathrm{CpG}$ island of both $\mathrm{p} 15^{\mathrm{INK}} 4 \mathrm{~b}$ and the RB1 gene are fully unmethylated in all samples tested including HCC and corresponding non-cancerous tissues along with the normal liver tissues, indicating that any functional loss of RB or p15INK4b in human HCC is not mediated by the methylation based gene silencing mechanism that operates in several other tumor types[35]. In sharp contrast, hypermethylation of the promoter $\mathrm{CpG}$ island of the p16 INK4a gene occurs overwhelmingly in HCC samples $(17 / 29,58.6 \%)$ and less frequently in adjacent non-cancerous tissues $(6 / 29,20.1 \%)$ (Additional file 2, additional file 3); while, it was unmethylated in all of the normal liver tissues. Since carcinogenesis is a progressive and multistage process and the so-called non-cancerous tissues classified pathologically may have already suffered some of the genetic or/and epigenetic abnormalities which are not unique to full-blown cancers. Any detectable abnormalities exclusively in tumor tissues probably represent the genetic or epigenetic lesion specific to the late-stage of tumorgenesis. Hence, hypermethylation of the promoter $\mathrm{CpG}$ island that was likely responsible for functional loss of the p $16^{\text {INK4a }}$ gene in human HCC (Fig. 1 and 2 and Additional file 2) is probably the very last definable lesion in this disease and makes the p16INK4a gene a suitable target for early diagnosis and genetic therapeutic remedies of HCC in China.

The hypermethylated promoter CPG island of the RASSFI a gene coexists with the unmethylated promoter CPG island of the RASSFIC genes in the human HCC in China

RASSF1 is a recently identified tumor suppressor acting at downstream of the Ras mediated apoptotic pathway and capable of binding to Ras in a GTP dependent manner[36]. It has two main variants, i.e., a and c, the results of the alternative initiation of transcription along with alternative splicing of the primary transcripts. RASSF1a has a more extended 5' part and its promoter CpG island displays a tumor specific hypermethylated profile in a variety 
of tumors, lung cancer in particular $[26,37,38]$. Furthermore, lack of RASSF1a expression in nineteen established tumor cell lines correlates with the hypermethylated state of its promoter CpG island [38]. RASSF1c has its own promoter $\mathrm{CpG}$ island, but is not methylated in any tumors. As shown in Fig. 1 and Additional file 2, additional file 3, the RASSF1a promoter-CpG island was methylated in all tumor cases $(29 / 29,100 \%)$, but less frequently methylated in the adjacent non-cancerous liver tissues (24/29, $82.75 \%)$. This CpG island was not methylated in any of the four normal liver tissue samples. On the contrary, the promoter $\mathrm{CpG}$ island of the $\mathrm{C}$ variant was unmethylated in the entire batch of samples tested. This observation was in accord with a previous report on human small-cell lung cancer, where $22 / 29$ cases $(79 \%)$ had fully methylated $1 \mathrm{~A}$ along with unmethylated 1C variants [38]. Different mechanisms are likely involved in the inactivation of the RASSF1a and 1c genes, if any, in human HCC.

CASP8 is frequently methylated in both cancerous and non-cancerous tissues of human HCC

CASP8, a cysteine protease is regulated in both death-receptor-dependent and independent manners during apoptosis. Its functional loss was previously attributed to a DNA methylation mechanism in as many as $61 \%$ of human neuroblastoma cases [21]. As indicated in Fig. 1 and 2; Additional file 2, the promoter CpG island of the CASP8 gene was fully methylated in all tissues from the HCC patients tested whereas unmethylated in all four normal liver tissues from healthy donors. This suggested that the methylated based mechanism may contribute exclusively to its inactivation in the methylated HCC cases in China.

While $\mathrm{CDHI}$ is unmethylated, $\mathrm{CDH} 33$ is significantly methylated in human HCC

The cadherins are a family of cell surface glycoproteins responsible for selective cell recognition and adhesion $[18,20,23,24]$. Within this family, both CDH1 (E-cadherin) and CDH13 (H-cadherin) have been implicated in invasion and metastasis by various solid tumors. Decreased expression of these two genes results in cell scattering and reduced intercellular interaction which were thought to promote tumor progression and invasion. Recent studies reported that methylation mediated gene silencing was a common alternative to genetic changes for functional loss of these two genes in human tumors $[18,20,23,24]$. For instance, the methylation mediated inactivation of the CDH13 gene occurred in 33\% of breast cancers and $35.5 \%$ of tested established tumor cell lines [39]. Furthermore, there is excellent concordance between the hypermethylated state of the promoter CpG island and lack of expression of the CDH 13 in both tumors and cell lines. For the first time, the methylation state of the promoter $\mathrm{CpG}$ islands of these two genes was examined in our re- port. As shown in Fig. 1 and Additional file 2, additional file 3, whereas the promoter $\mathrm{CpG}$ island of the CDH1 gene was uniformly unmethylated, tissues from 6/29 (20\%) hepatoma cases and 5/29 (17.24\%) matching noncancerous tissues revealed hypermethylated CDH13 DNA. Therefore, the methylation of the CDH13 gene rather than CDH1 had some hepatoma-specific property and may have contributed in part to the functional loss of the CDH13 gene in human HCC.

\section{Can methylation mediated mechanism co-operate with other genetic mechanisms for the tumor specific aberrant gene expression of the same gene?}

It has been well recognized that the so-called non-cancerous cells defined under microscope may have already suffered some genetic lesions as have the corresponding cancerous tissues, the outcome of earlier oncogenic events. Both the molecular genetic diversity of tumorigenic cells at various stages and the intermingled presence of normal with tumor cells can lead to cross-contamination of the so-called normal tissues adjacent to cancerous samples and vise versa, which are commonly used in similar studies. Although special efforts have been made to improve the quality of the samples in this study, it was not possible to entirely eliminate cross-contamination during our sampling process. Therefore, it is difficult to determine if the coexistence of the methylated and unmethylated target DNA segments (Fig. 1 and 2; Additional file 2) was an inevitable consequence of cross-contamination between tumor tissue and non-cancerous samples or a genuine reflection of the in vivo situation.

There are several strong arguments for the latter claim. First, over twenty genes were studied in parallel, and the observed pattern of methylation varies dramatically with the target segments. Second, MSP is a very sensitive method that can detect very low level contamination of DNA that otherwise absent in patient samples. It is highly unlikely that cross-contamination could create the observed heterozygosity in the methylation profiles. Furthermore, the methylation pattern of the promoter CpG island of the p16INK4a gene varied significantly with tissues samples, even between cancerous and corresponding noncancerous samples from the same patient (Fig. 1 and 2; Additional file 2). Finally, the RASSF1a gene was comparably methylated to various extents between the cancerous and non-cancerous tissues while its variant, RASSF1c, was fully unmethylated in each case.

Therefore, coexistence of the methylated and unmethylated DNA in same patient samples, of p16INK4a, RASSF1a and CDH1 genes, reflect the in vivo situation and have some functional significance. HCC specific inactivation of these three genes may indeed be attributed to both epigenetic and genetic mechanism. 
Table 4: Cirrhosis and methylation profiles of the genes in HCC-2

\begin{tabular}{|c|c|c|c|c|c|}
\hline \multirow[t]{2}{*}{ Cirrhosis } & \multirow[t]{2}{*}{ Tissue samples } & \multicolumn{2}{|c|}{ pI 6INK4a } & \multicolumn{2}{|c|}{ CDHI3 } \\
\hline & & $U$ & $M$ & $U$ & $M$ \\
\hline \multirow[t]{2}{*}{ - $(44.8 \%)$} & $N$ & II (84.62\%) & $2(15.38 \%)$ & $9(69.23 \%)$ & $4(30.77 \%)$ \\
\hline & $C$ & $9(69.23 \%)$ & $4(30.77 \%)$ & $9(69.23 \%)$ & $4(30.77 \%)$ \\
\hline \multirow[t]{2}{*}{$+(55.2 \%)$} & $\mathrm{N}$ & $12(75.00 \%)$ & $4(25.00 \%)$ & $15(93.75 \%)$ & I (6.25\%) \\
\hline & C & $4(25 \%)$ & $12(75 \%)$ & | 4 (87.50\%) & 2 (I $2.50 \%)$ \\
\hline
\end{tabular}

Hypermethylation of the promoter CPG island of the p I 6 INK4a and RASSFI a genes is closely linked to cirrhosis in hepatocellular carcinoma patients in China

Methylation mediated gene silencing is a common alternative to the genetic lesion of genes for tumor specific aberrant gene expression. Inclusion of the corresponding non-cancerous tissues in this study allowed us to address the question as to the stage-related aspects of hypermethylation of the promoter $\mathrm{CpG}$ island during the process of carcinogenesis in human HCC. In this regard, we found that p16 ${ }^{\text {INK4a }}$ was heavily methylated in the tumor (17/ $29,58.6 \%)$, but much less in the matched non-cancerous tissues (4/29, 13.3\%; Additional file 2, and additional file 3 ). The simplest explanation is that hypermethylation of the $\mathrm{p} 16^{\mathrm{INK}} 4 \mathrm{a}$ promoter $\mathrm{CpG}$ island is a very late event in hepatocarcinogenesis. On the contrary, the frequency of hypermethylation of the RASSF1a promoter in tumor (29/ $29,100 \%$ ) is only slightly more than that in the corresponding non-cancerous tissues (24/29, 82.75\%; Additional file 2, and additional file 3 ). If the same logic is applied, the methylation of the RASSF1a promoter CpG island occurs earlier than the same event involving the p16 INK4a gene in human HCC.

For the first time, the methylation profile of the promoter $\mathrm{CpG}$ islands of as many as twenty genes with proven roles in carcinogenesis have been analyzed in human hepatocarcinoma in China; this enabled us to determine if there is any association in the methylation profiles among the genes being studied as well as the gene methylation with the clinical pathological parameters of HCC. As shown in Additional file 2, and additional file 3, no apparent associations were revealed in the methylation profile of each of these four genes with the majority of the clinical-pathological parameters including age, geographic origin, level of AFP in serum, size of tumors as well as whether metastasis accompanied the primary lesion. On the contrary, a close link was detected between the methylation profiles of p16INK4a and CDH13 genes with liver cirrhosis of HCC patients. As summarized in Tables 3 and 4, the methylation of the CDH13 gene occurs at a significantly higher frequency in non-cirrhotic $(5 / 13,30.76 \%)$ than cirrhotic patients $(1 / 16,6.25 \%)$ [Note, as the sample size is relatively small, the association may not be statistically significant]. The opposite correlation is true for the p16INK4a gene where methylated DNA was more frequently found in the cirrhotic $(12 / 16,75 \%)$ than the non-cirrhotic group $(4 / 13,33.3 \%)$. A similar conclusion was drawn with the non-cancerous liver tissues (Table 4). Although the underlying mechanism for such close links among these three parameters is not clear at the present time, such information would certainly have substantial diagnostic value. It is desirable to extend our study described in this report to more patients prior to the intensive efforts in unveiling the mystery of molecular genetic mechanisms underscoring human hepatocarcinogenesis in China.

\section{Abbreviations used}

AFP: alpha-fetoprotein; HCC: Hepatocellular carcinoma; PCR: polymerase chain reaction; MSP: methylation specific PCR; HBV: hepatitis B virus; TSP: tumor suppressor protein; APC: adenomatosis polyposis coli; BRCA1: breast cancer 1; CDH1: cadherin type 1, E-cadherin; hTERC: Telomerase RNA component; RARB: retinoic acid receptor, beta; p14ARF: the alternative reading frame of the cyclindependent kinase inhibitor $4 \mathrm{a}$; p15 INK4b: cyclin-dependent kinase inhibitor 4b; VHL: von Hippel-Lindau syndrome; CASP8: caspase 8, apoptosis-related cysteine protease; CDH13: cadherin 13, H-cadherin; p16INK4a: cyclin-dependent kinase inhibitor 4a; TIMP3: tissue inhibitor of metalloproteinase 3; DAPK1: death-associated protein kinase 1; PTEN: phosphatase and tensin homolog; RB1: retinoblastoma 1; APAF1: apoptotic protease activating factor; hMLH1: mutL homolog 1 , colon cancer, nonpolyposis type 2; RASSF1a: ras association (RalGDS/AF-6) domain family 1 protein isoform 1a; RASSF1c: ras association (RalGDS/AF-6) domain family 1 protein isoform $1 \mathrm{c}$

\section{Competing interests}

None declared.

\section{Authors' contributions}

Jian $\mathrm{Yu}$, Min Ni, Jian Xu, Hongyu Zhang, Baomei Gao: Jianren $\mathrm{Gu}$ : executing the experiments; Jianguo Chen, 
Lisheng Zhang, Mengchao Wu, Sushen Zhen: providing the patient samples; Jingde Zhu: designing and organizing experiments as well as completing manuscripts.

\section{Additional material}

\section{Additional File 1}

Target $C p G$ islands and the primers for MSP.

Click here for file

[http://www.biomedcentral.com/content/supplementary/1471-

2407-2-29-S1.doc]

\section{Additional File 2}

Methylation profile of twenty genes in human HCC patients.

Click here for file

[http://www.biomedcentral.com/content/supplementary/14712407-2-29-S2.xls]

\section{Additional File 3}

Clinical pathological parameters and methylation profiles of the genes in HCC.

Click here for file

[http://www.biomedcentral.com/content/supplementary/14712407-2-29-S3.doc]

\section{Acknowledgements}

This work is supported by the 973 project of China(GI 99805 I004) to Jingde Zhu. Thanks are due to Zhonghua Tang, Yang Shen, Shuo Zhang for their technical assistanc, and Jianyi Guo for statistical analyses of the data.

\section{References}

I. Liu Q, Wang W and eds Liver Cancer. Beijing: People's Medical Publishing House 2000,

2. Parkin DM, Whelan SL, Ferlay J, Raymond L, Young J and eds IARC library cataloguing in publication data cancer incidence in five continents, no. 143 edn. Lyon: IARC Scientific Publications 1997.

3. Chen CJ, Yu MW and YF L Epidemiological characteristics and risk factors of hepatocellular carcinoma. J Gastroenterol Hepatol 1997, I 2:S294-308

4. Feninberg $A$ Cancer epigenetics takes center stage. Proc Natl Acad Sci USA 2001, 98:392-394

5. Feinberg A DNA methylation, genomic imprinting and cancer. Curr Top Microbiol Immunol 2000, 249:87-99

6. Paulsen $M$ and Ferguson-Smith AC DNA methylation in genomic imprinting, development, and disease. J Pathol 200I, I 95:97110

7. Baylin SB and Herman JG DNA hypermethylation in tumorigenesis: epigenetics joins genetics. Trends Genet 2000, I 6: I68-174

8. Jones PA and D T The role of DNA methylation in mammalian epigenetics. Science 200I, 293:1068-70

9. Baldwin RL, Nemeth E, Tran H, Shvartsman H, Cass I, Narod S and Karlan BY BRCAI promoter region hypermethylation in ovarian carcinoma: a population-based study. Cancer Res 2000, 60:5329-5333

10. Simpson DJ, Hibberts NA, McNicol AM, Clayton RN and Farrell WE Loss of $\mathbf{p R b}$ expression in pituitary adenomas is associated with methylation of the RBI CpG island. Cancer Res 2000, 60:1211-1216

II. Wiencke JK, Zheng S, Lafuente A, Lafuente MJ, Grudzen C, Wrensch MR, Miike R, Ballesta $A$ and Trias $M$ Aberrant methylation of pI 6INK4a in anatomic and gender-specific subtypes of sporadic colorectal cancer. Cancer Epidemiol Biomarkers Prev 1999, 8:501-506
12. Lin CH, Hsieh SY, Sheen IS, Lee WC, Chen TC, Shyu WC and Liaw YF Genome-wide hypomethylation in hepatocellular carcinogenesis. Cancer Res 200I, 6 I:4238-4243

13. Chen RZ, Pettersson U, Beard C, Jackson-Grusby $L$ and Jaenisch $R$ DNA hypomethylation leads to elevated mutation rates. $\mathrm{Na}$ ture 1998, 395:89-93

14. Wong IH, Lo YM, Yeo W, Lau WY and Johnson PJ Frequent pI5 promoter methylation in tumor and peripheral blood from hepatocellular carcinoma patients. Clin Cancer Res 2000, 6:35 I 63521

15. Wong IH, Lo YM, Zhang J, Liew CT, Ng MH, Wong N, Lai PB, Lau WY, Hjelm NM and Johnson PJ Detection of aberrant p 16 methylation in the plasma and serum of liver cancer patients. Cancer Res 1999, 59:71-73

16. Wong DJ, Foster SA, Galloway DA and Reid BJ Progressive regionspecific de novo methylation of the p 16 CpG island in primary human mammary epithelial cell strains during escape from M(0) growth arrest. Mol Cell Biol 1999, 19:5642-565 I

17. Hoare SF, Bryce LA, Wisman GB, Burns S, Going JJ, van der Zee AG and Keith WN Lack of telomerase RNA gene hTERC expression in alternative lengthening of telomeres cells is associated with methylation of the hTERC promoter. Cancer Res 2001 , 61:27-32

18. Herman JG, Graff JR, Myohanen S, Nelkin BD and Baylin SB Methylation-specific PCR: a novel PCR assay for methylation status of CpG islands. Proc Natl Acad Sci U S A 1996, 93:982I-9826

19. Xing EP NY, Song Y, Yang GY, Cai YC, Wang LD and Yang CS Mechanisms of inactivation of pI 4ARF, pI5INK4b, and pI 6INK4a genes in human esophageal squamous cell carcinoma. Clin Cancer Res 1999, 5:2704-13

20. Chung WB, Hong SH, Kim JA, Sohn YK, Kim BW and JW K Hypermethylation of tumor-related genes in genitourinary cancer cell lines. J Korean Med Sci 200I, I 6:756-6I

21. Teitz T, Wei T, Valentine MB, Vanin EF, Grenet J, Valentine VA, Behm FG, Look AT, Lahti JM and Kidd VJ Caspase 8 is deleted or silenced preferentially in childhood neuroblastomas with amplification of MYCN. Nat Med 2000, 6:529-535

22. Esteller M, Sparks A, Toyota M, Sanchez-Cespedes M, Capella G, Peinado MA, Gonzalez S, Tarafa G, Sidransky D, Meltzer SJ, Baylin SB and JG Herman Analysis of adenomatous polyposis coli promoter hypermethylation in human cancer. Cancer Res 2000, 60:4366437I

23. Zochbauer-Muller S, Fong KM, Virmani AK, Geradts J, Gazdar AF and Minna JD Aberrant promoter methylation of multiple genes in non-small cell lung cancers. Cancer Res 200 I, 6 I:249-255

24. Graff JR, Herman JG, Myohanen S, Baylin SB and Vertino PM Mapping patterns of $\mathrm{CpG}$ island methylation in normal and neoplastic cells implicates both upstream and downstream regions in de novo methylation. J Biol Chem 1997, 272:2232222329

25. Rosas SL, Koch W, da Costa Carvalho MG, Wu L, Califano J, Westra W, Jen J and Sidransky D Promoter hypermethylation patterns of p 16, O6-methylguanine-DNA-methyltransferase, and death-associated protein kinase in tumors and saliva of head and neck cancer patients. Cancer Res 200I, 6 I :939-942

26. Lo KW, Kwong J, Hui AB, Chan SY, To KF, Chan AS, Chow LS, Teo PM, Johnson PJ and Huang DP High frequency of promoter hypermethylation of RASSFIa in nasopharyngeal carcinoma. Cancer Res 2001, 6 1:3877-3881

27. Hattori M, Sakamoto $H$, Satoh $K$ and Yamamoto T DNA demethylase is expressed in ovarian cancers and the expression correlates with demethylation of CpG sites in the promoter region of c-erbB-2 and SURVIVIN genes. Cancer Lett 200I, 169:155-164

28. Soengas MS, Capodieci P, Polsky D, Mora J, Esteller M, Opitz-Araya X, McCombie R, Herman JG, Gerald WL, Lazebnik YA, Cordon-Cardo $C$ and Lowe SW Inactivation of the apoptosis effector Apaf I in malignant melanoma. Nature 200 I, 409:207-2 I I

29. Bian J, Wang Y, Smith MR, Kim H, Jacobs C, Jackman J, Kung HF, Colburn $\mathrm{NH}$ and Sun $\mathrm{Y}$ Suppression of in vivo tumor growth and induction of suspension cell death by tissue inhibitor of metalloproteinases (TIMP3). Carcinogenesis 1996, I 7: | 805- I8I I

30. Sherr C Cancer Cell Cycles. Science 1996, 274:1672-2677

31. Foster SA, Wong DJ, Barrett MT and Galloway DA Inactivation of p 16 in human mammary epithelial cells by CpG island methylation. Mol Cell Biol 1998, I 8: I793-I80I 
32. Hannon $G$ J and Beach D pI5INK4b is a potential effector of TGF-beta-induced cell cycle arrest. Nature 1994, 37 I:257-26 I

33. Stone S DP, Jiang P, Weaver-Feldhaus JM, Tavtigian SV, Cannon-Albright $L$ and Kamb $A$ Genomic structure, expression and mutational analysis of the PI 5 (MTS2) gene. Oncogene 1995, I I:987991

34. Quesnel B, Guillerm G, Vereecque R, Wattel E, Preudhomme C, Bauters $F$, Vanrumbeke $M$ and Fenaux $P$ Methylation of the pI5(INK4b) gene in myelodysplastic syndromes is frequent and acquired during disease progression. Blood 1998, 91 1:29852990

35. Merlo A HJ, Mao L, Lee DJ, Gabrielson E, Burger PC, Baylin SB and Sidransky D 5' CpG island methylation is associated with transcriptional silencing of the tumour suppressor p /6/CDKN2/ MTSI in human cancers. Nat Med 1995, I:686-692

36. Gupta AK, Bakanauskas VJ, Cerniglia GJ, Cheng Y, Bernhard EJ and Muschel RJ McKenna WG: The Ras radiation resistance pathway. Cancer Res 200I, 6I:4278-4282

37. Agathanggelou A, Honorio S, Macartney DP, Martinez A, Dallol A, Rader J, Fullwood P, Chauhan A, Walker R, Shaw JA, Hosoe S, Lerman MI, Minna JD, Maher ER and Latif $F$ Methylation associated inactivation of RASSFIa from region $3 \mathrm{p}^{2} \mathrm{I} .3$ in lung, breast and ovarian tumours. Oncogene 200I, 20:1509-1518

38. Dammann R, Takahashi T and Pfeifer GP The CpG island of the novel tumor suppressor gene RASSFIa is intensely methylated in primary small cell lung carcinomas. Oncogene 200I, 20:3563-3567

39. Toyooka KO TS, Virmani AK, Sathyanarayana UG, Euhus DM, Gilcrease M, Minna JD and Gazdar AF Loss of expression and aberrant methylation of the CDHI3 (H-cadherin) gene in breast and lung carcinomas. Cancer Res 200 I, 6 I:4556-4560

40. Japan LCSGo TNM classification for hepatocellular carcinoma by Liver Cancer Study group. World J Surg 1989, 13:212

41. Nguyen CT, Gonzales FA and Jones PA Altered chromatin structure associated with methylation-induced gene silencing in cancer cells: correlation of accessibility, methylation, MeCP2 binding and acetylation. Nucleic Acids Res 2001, 29(22):4598-606

42. Lin YW, Chen CH, Huang GT, Lee PH, Wang JT, Chen DS, Lu FJ and Sheu JC Infrequent mutations and no methylation of CDKN2A (PI6/MTSI) and CDKN2B (pI5/MTS2) in hepatocellular carcinoma in Taiwan. Eur J Cancer 1998, 34(I I): I789-95

43. Zhu JD, Allan M and Paul J The chromatin structure of the human epsilon globin gene: nuclease hypersensitive sites correlate with multiple initiation sites of transcription Nucleic Acids Res 1984, 12:9191-9204

\section{Pre-publication history}

The pre-publication history for this paper can be accessed here:

http://www.biomedcentral.com/1471-2407/2/29/prepub
Publish with Bio Med Central and every scientist can read your work free of charge

"BioMed Central will be the most significant development for disseminating the results of biomedical research in our lifetime. "

Sir Paul Nurse, Cancer Research UK

Your research papers will be:

- available free of charge to the entire biomedical community

- peer reviewed and published immediately upon acceptance

- cited in PubMed and archived on PubMed Central

- yours - you keep the copyright
BioMedcentral 